\title{
"Empresarização" e controle: o caso do Figueirense Futebol Clube $^{1}$
}

\section{"Empresarização" and Control: the Case of the Figueirense Soccer Club}

Julio Cesar de Santana Gonçalves ${ }^{2}$

Carlos Everaldo Silva

\section{Resumo}

Este artigo analisa como o processo de "empresarização" no Figueirense Futebol Clube (SC) influencia seus mecanismos de controle organizacional. Aqui, entende-se "empresarização" como o processo pelo qual uma organização adota características e traços típicos de organizações empresariais. 0 artigo caracteriza-se como descritivo-interpretativo, e a escolha desse clube deu-se de modo intencional e não probabilístico, porque reúne características que permitem situá-lo como caso ilustrativo das questões que permeiam este estudo e dada a sua representatividade no atual cenário futebolístico brasileiro.

Neste estudo se percebeu que o clube de futebol tem modificado seus mecanismos de gestão e de controle, adaptando-se aos elementos caracterizadores da expansão da lógica de mercado presentes no ambiente. A perda da dimensão substantiva de atividades como o futebol é a preocupação de fundo que perpassa este artigo. Este questiona sobre o que irá substituir as práticas desportivas e também a cultura e o ócio na cimentação social dos indivíduos, bem como seus laços de pertença e a sua identidade cultural.

Palavras-chave: "Empresarização"; Controle; Figueirense Futebol Clube.

\section{Abstract}

This work analyzes of that it forms the process of "empresarizacion" in Figueirense Futebol Club (SC) exerts influence on its mechanisms of organizational control. "empresarizacion" is understood, here, as the process for which an organization adopts characteristics and typical traces of enterprise organizations. The present study it is characterized as descriptioninterpretative. The choice of this club was given in intentional and not probabilistic way, because it congregates characteristics that allow to point out it as case to illustrate the questions that are part of this study and given its representation in the current Brazilian football scene. It was perceived, in this study, that the soccer club has modified its mechanisms of management and control, and so to adapt itself it the elements that it characterizes of the expansion of the market logic gifts in the environment. The loss of the substantive dimension of activities as the soccer is the concern of deep that it seats this work, that questions on what it will go to also substitute practical porting but the culture in the social face-hardenings of the individuals, its bows of belongs and its cultural identity.

Key words: "Empresarizacion"; control; Figueirense Soccer Club.

1 Este artigo foi apresentado e aprovado no IV Encontro Nacional de Estudos Organizacionais, Porto Alegre (RS), jun. 2006.

2 Mestre em Administração pela UFPE. Professor da Faculdade do Vale do Ipojuca - FAVIP (Caruaru-PE) e Professor da Faculdade Européia(FEPAM-PE) Endereço: Avenida Quatro, 55-B, Vila Rica - 54090-470 - Jaboatão dos Guararapes - PE - julio.goncalves1@uol.com.br

3 Mestre em Administração pela Universidade Federal de Santa Catarina - UFSC. Professor da Universidade Federal de Alagoas, Campus Arapiraca - Endereço que possa ser publicado - Rua Presidente Agostinho da Silva Neves, 0.05, 986, POçO, CEP. 57025245, Maceió-Al - c_everaldo@hotmail.com

Artigo recebido em julho de 2006 e aceito para publicação em novembro de 2006 


\section{Introdução}

O futebol pode ser considerado um esporte de ampla aceitação no Brasil e que gera debates na nossa sociedade em diferentes âmbitos. Do mesmo modo que comentam e discutem, as pessoas também praticam o futebol de várias formas. Numa primeira dimensão, tem-se o futebol praticado como um "joguinho", uma "pelada" ou "rachinha" na porta de casa - segundo denominações populares - jogado descalço, com pares de sandálias utilizados como "travessões" e no qual os jogadores são identificados pelo uso ou não de camisas. Igualmente, há os jogos em campos alugados com os amigos - com seus jogadores muitas vezes uniformizados - até chegarmos aos campeonatos amadores promovidos em bairros comunitários. Numa segunda dimensão, temos o futebol profissional, em que há ligas estaduais, nacionais e internacionais com lógicas de organização diferentes.

A primeira dimensão do futebol parte do princípio de um jogo lúdico que se pode aproximar daquilo que Ramos (1989) chama de prática substantiva, na sua distinção entre racionalidade substantiva e instrumental. Nesse caso, há apenas o prazer de praticar o futebol. As relações de identidade e o compartilhamento de valores são aspectos importantes nessa dimensão.

Na segunda dimensão do futebol, as relações são modificadas e, embora laços de identidade não desapareçam de todo, questões profissionais e relações instrumentais começam a ter preponderância. Essa transformação parece vir se acentuando nos dias de hoje, à medida que os clubes se aproximam mais do mercado. Sob essa dimensão, Carvalho (2003, p.252) afirma que

isso decorre do fato das organizações desportivas estarem incorporando novos significados aos seus agentes e instituições, frutos da paulatina ampliação de uma lógica orientadora das ações de mercado, que se reflete em diversas áreas como o torcedor, o jogador, o jogo, o estádio e os relacionamentos.

A adoção de uma lógica orientadora das ações de mercado faz com que os clubes de futebol adotem mecanismos empresariais de gestão.

Apesar de muitos estudos sobre futebol já terem sido feitos, pretende-se contribuir, aqui, com um estudo no qual se observou como os atores envolvidos com o futebol se comportam em relação aos mecanismos empresariais e sua relação com o controle interno das organizações futebolísticas. A adoção de mecanismos empresariais parece relevante na medida em que indica um processo de mercantilização crescente. A inserção de mecanismos empresariais na disposição de algumas organizações pode ter impacto sobre diversos processos desenvolvidos nas mesmas. Um desses processos é o controle. O controle é um processo analisado por muitos autores como central no fenômeno organizacional, e alguns destes chegam a sugerir que organização seria sinônimo de controle. Assim, este artigo investiga a relação entre o processo de "empresarização" de um clube de futebol do estado de Santa Catarina e as transformações no que tange ao controle organizacional.

Tais questionamentos se devem ao fato de que, em que pese toda a carga cultural, lúdica e popular do futebol, percebe-se que diversas são as transformações sociais que têm ocorrido no ambiente das organizações desportivas; transformações essas que têm influenciado as formas de gestão dessas organizações. A inserção da lógica de mercado como um discurso dominante nos esportes em geral tem feito com que o jogo em si passe a ocupar uma posição secundária em relação a aspectos como estatísticas, cálculos e regras, haja vista a crescente necessidade de adequação das organizações esportivas ao esquema capitalista dominante na sociedade. Atualmente, o futebol é tratado como um produto, refletindo o conflito entre a lógica do mercantilismo e os valores do esporte, pois o futebol lúdico tem dado lugar a aspectos pragmáticos do lucro.

O objetivo deste artigo, então, é analisar de que forma o processo de "empresarização" no Figueirense Futebol Clube exerce influência sobre os seus mecanismos de controle organizacional. Aqui, "empresarização" é entendida como o processo pelo qual as organizações futebolísticas adotam características e traços típicos de organizações empresariais (SOLÉ, 2004). Sob influência de fatores de mercado são exigidos novos padrões de ação, e os clubes começam a aderir ao modelo de organização empresarial. 
Desse modo, como eixo predominante do marco teórico, esta análise apóia-se nos conceitos e abordagens sobre racionalidade instrumental e lógica de mercado, "empresarização" e controle organizacional. Argumenta-se que os clubes de futebol produzem mudanças nos seus mecanismos de gestão e de controle, adaptando-se aos elementos caracterizadores da expansão da lógica de mercado presentes no ambiente.

Este artigo é derivado de uma análise feita nos clubes de futebol de Santa Catarina que atuaram na primeira divisão do Campeonato Estadual entre os anos de 2000 e 2004 e utiliza um caso exemplar/ilustrativo (o Figueirense Futebol Clube), por permitir a visualização de características diferentes dos aspectos que se pretende analisar. Desse modo, este estudo se enquadra no escopo daqueles que buscam entender o processo de mudanças na sociedade, como a perda de espaço das práticas de ócio livre, num contexto de amplo domínio do modelo capitalista de desenvolvimento, o qual traz consigo uma crescente subordinação à racionalidade instrumental que facilita o ajuste às leis de mercado.

\section{Racionalidade, "empresarização" e controle organizacional}

\section{Racionalidade instrumental como base das ações organizacionais}

Quando se identifica a lógica da ação, procura-se determinar qual o modo de agir de pessoas, grupos e organizações e quais os valores que os orientam. A idéia de racionalidade - ou a forma pela qual as pessoas e os grupos orientam suas ações - está relacionada com o conceito de ação social formulado por Max Weber. Por "ação social" entende-se uma ação em que o sentido indicado por seu sujeito (ou sujeitos) refere-se à conduta de outros, orientando-se por esta em seu desenvolvimento (WEBER, 2001).

Muito embora o estudo de Weber tenha considerado mais de um tipo de racionalidade, sua obra está baseada na racionalidade instrumental, no sentido de procurar entender o processo de racionalização das esferas da vida em sociedade. A noção de racionalidade instrumental traz consigo o caráter utilitarista da ação, que para existir precisa estar em conformidade com as leis e as regras de mercado. Ao enfatizar a simultaneidade da ação em vez de sua seqüência, Weber esclarece os múltiplos sentidos da ação em toda sua complexidade. Segundo Weber (2001), os tipos de ação social não se excluem; ou seja, um indivíduo pode participar de diferentes tipos de ação num mesmo ato. Assim, acredita-se que a ação humana e, conseqüentemente, as ações administrativas e a própria vida organizacional não se orientam exclusivamente por uma única lógica.

O conceito de racionalidade tem sido reconhecido como o componente mais importante do pensamento weberiano sobre o processo histórico de racionalização da sociedade. Dellagnelo e Machado-da-Silva (2000, p. 4) afirmam que esse conceito "está intimamente relacionado a toda a sua discussão sobre a de-magificação do mundo, a burocratização e a crescente perda de liberdade na sociedade moderna".

Com o advento da revolução industrial e a crescente onda migratória para os centros urbanos, a reorganização do trabalho levou as pessoas a se desvincularem de suas funções originais e a se submeterem a uma lógica diferente onde, em vez de serem produtores de bens e serviços, tornaram-se os meios de produção, operando como engrenagens de uma máquina, sob uma nova racionalidade que Weber (apud Kalberg, 1980) chamou de instrumental, baseada na adequação dos meios-fins. A ação instrumental baseada no cálculo utilitário das consequiências tem se legitimado em toda a sociedade e em especial no seio das organizações, onde a noção de maximização do retorno esperado assume uma posição de natureza imperativa (GONÇALVES; MAGALHÃES FILHO; ALCÂNTARA, 2003).

\section{0 conceito de "empresarização"}

Acredita-se que a sociedade que hoje está se delineando seja uma "sociedade de organizações", como afirmam Etzioni (1967, p.7) e Perrow (1990). Este usa a expressão para mostrar que as atividades que outrora foram executadas por pequenos grupos informais e relativamente autônomos (por famílias e por pequenas organizações autônomas), agora, estão sendo executadas por grandes burocracias. Desse modo, percebe-se que 
uma das características da sociedade contemporânea é o fato de ser constituída por um conjunto de organizações. Nesse sentido, os indivíduos têm hoje uma dependência muito grande das organizações (sobretudo das empresas); basta atentar para o dia-a-dia e constatar que a maior parte de nosso tempo passamos interagindo com vários tipos de empresas.

Para Weber (1987, p.105), "uma empresa é um sistema de atividade contínua perseguindo um fim de uma espécie definida", o qual, para Schumpeter (1988), está baseado no mecanismo de troca econômica. Assim, "uma ação será denominada economicamente orientada na medida em que, segundo seu sentido visado, esteja referida a cuidados de satisfazer o desejo de obter certas utilidades." (WEBER, 1991, p.37). Portanto, "a moderna empresa capitalista baseia-se fundamentalmente no cálculo e pressupõe um sistema administrativo e legal cujo funcionamento pode ser racionalmente calculado, em princípio, pelo menos, em virtude de suas normas gerais fixas." (WEBER, 1997, p.41).

Na visão de Solé (2004), a empresa é uma organização econômica, social, política, psicossocial, jurídica etc., o que supõe um enfoque transdisciplinar. A empresa, segundo esse autor, pode ser caracterizada em função da percepção de 22 características relatadas como uma forma de "tipo ideal de empresa". Para Solé (2004), o tipo ideal é uma pintura, uma criação do investigador. O tipo ideal refere-se a "uma construção puramente idealizada, uma abstração orientada pelos valores do pesquisador, em relação aos quais se estuda um determinado fenômeno a fim de se esclarecer o conteúdo empírico de alguns dos seus elementos constituintes." (ALVES, 2003, p.23).

Partindo do tipo ideal de empresa, Solé (2004) afirma que a empresa é uma organização que concebe, produz e vende mercadorias; uma organização com moeda, capital e benefício econômico; uma organização com escritura e contabilidade; uma propriedade privada movida por fins econômicos e uma organização salarial. A empresa é uma organização que produz uma linguagem própria.

Diante dessas questões, salienta-se que Andreu Solé, professor pesquisador da École de Hautes Études Commerciales (HEC), na França, partindo da pergunta de Coase, economista do Reino Unido premiado com o Prêmio de Ciências Econômicas em 1991, sobre "por que uma empresa existe?", desenvolve seus argumentos sobre a "empresarização" do mundo, de uma perspectiva histórica (ainda em curso), ao discutir sobre quando, onde e como a empresa aparece na história da humanidade (SOLÉ, 2003, 2004). Esse pesquisador mostra que várias organizações têm aderido ao modelo empresarial e adotam instrumentos, ferramentas, métodos, linguagem e até concepção de tempo próprios de organizações empresariais. Os serviços públicos, por exemplo, mudaram a expressão "usuários" para "clientes"; as associações humanitárias recorrem aos métodos de marketing; enquanto os hospitais e as escolas têm importado sofisticados sistemas de controle de gestão empresarial (SOLÉ, 2003, 2004).

Ao citar o jornal Le Monde, de 30 de setembro e 1 de outubro de 2001, esse autor mostra um artigo intitulado "O Juventus de Turin quer ser uma empresa", que retrata o caso de um clube de futebol que preparou sua entrada na Bolsa de Milão, enquanto os acionistas do clube aprovaram a entrada num mercado com mais de $35 \%$ de seu capital, visando explorar o "mercado" futebolístico. Já no exercício 2000/01, o clube registrara 5,8 milhões de euros de rendimentos (lucro), o que equivaleu a uma alta de 5\% sobre o exercício precedente.

O que se percebe, atualmente, é que a empresa tem se afirmado como modelo de quase todas as atividades humanas (SOLÉ, 2003, 2004). Para esse autor, nosso mundo é um "mundo-empresa", um mundo organizado para e pela empresa. Ao entender modelo como exemplo, norma e referência obrigatória, esse pesquisador afirma que "empresarização" é o processo histórico no qual se percebe que a empresa é um modelo universal de organização.

Solé (2004) salienta ainda um conjunto de manifestações contemporâneas que parecem corroborar seus argumentos sobre o processo de "empresarização" do mundo. Percebe-se, por exemplo: 
- que nossas condições de vida (habitação, alimentação - comprar pratos preparados, vestimentas, cuidar dos anciãos etc.) são cada vez mais concebidas e produzidas pelas empresas;

- o crescente número de privatizações em todo o mundo; ou seja, a transformação de organizações públicas em empresas;

- a transformação de outras organizações em empresas (como é o caso do Manchester United, clube inglês, e dos clubes-empresas existentes no Brasil, a exemplo do Bahia S.A.);

- extensão da linguagem de empresa a todas as atividades e relações humanas (exemplo: mercadoria, produto, clientela, eficiência e competitividade);

- mercantilização (muitas atividades se transformam em mercadorias, como acredita-se ser o caso do futebol brasileiro); e

- a subordinação crescente de outras organizações (Estado, escolas, igrejas, o futebol) a um modelo empresarial de estruturação e funcionamento.

Tais exemplos foram citados com o intuito de ilustrar os aspectos/argumentos até aqui apresentados. Não é do interesse desta reflexão teórico-empírica avançar nas discussões sobre esses apontamentos. No entanto, o que se assiste hoje, em nossa sociedade, é a hegemonia do econômico, fundada na propriedade privada, no jogo de interesses pessoais, na busca do lucro e da acumulação que se impôs gradualmente por toda a parte. Percebe-se que cada vez mais os fatores de mercado ampliam sua influência abrangendo organizações que até então pareciam estar alienadas a essas modificações. Nesse contexto, estão as organizações que atuam no campo do desporto. Os clubes de futebol, por exemplo, têm paulatinamente incorporado novas ações e novos agentes no seu campo de atuação. Essas novas ações e esses novos agentes são adotados mediante padrões e critérios racionalmente instrumentalizados, normalmente, comuns às organizações empresariais e que direcionam a ação desses clubes no novo mercado.

Mediante a adoção de critérios associados a uma maior eficiência, os clubes de futebol produzem um deslocamento na ação que pode ser percebido no nível de especialização e formalização do trabalho, na modelagem da sua estrutura interna de funcionamento, na adoção de critérios técnico-científicos no relacionamento com o mercado, no delineamento de planos formais de estratégia e na busca por uma gestão eficiente dos recursos financeiros. Esses aspectos foram observados no estudo desenvolvido por Magalhães Filho (2003). Assim, essa crescente racionalização contribui para a incorporação de novos agentes no âmbito de negócio do futebol. Empresas de marketing esportivo, instituições financeiras, organizações privadas interessadas no retorno da marca e outros clubes de futebol são inseridos com o intuito de, uma vez estabelecidas ações de natureza comercial, maximiza-se o retorno financeiro do clube, o que demonstra que os aspectos de negócio assumem uma posição determinante para sua sobrevivência.

\section{Considerações sobre controle organizacional}

Tannenbaum (1975, p.15) afirma que "caracterizar uma organização de acordo com o seu padrão de controle é descrever um aspecto essencial e universal da organização que cada membro deve enfrentar e ao qual deve ajustar-se". Assim, organização implica controle. Mesmo não sendo um conceito novo para o estudo das organizações, não há um conceito universal para o controle (HOFSTEDE, 1981). Estar numa situação de controle, segundo Chiapello (1996), significa que o comportamento de uma pessoa é influenciado por seu próprio grupo de indivíduos. Dentre as várias abordagens existentes, três autores abordam o controle de forma evolutiva. Tanennbaum (1975, p.18) define controle como "qualquer processo no qual uma pessoa, grupo de pessoas ou organizações de pessoas determinam e intencionalmente afetam o comportamento de outra pessoa, grupo ou organização". Chiapello (1996), por outro lado, define o controle como uma influência criadora de ordem, e Silva (2003, p.800) o define como "um processo de busca de redução de incerteza", destacando, assim, o controle, de uma forma ampla e sistêmica. 
Depois de chamar atenção para algumas definições sobre controle, aborda-se adiante sua evolução nas organizações, partindo dos mecanismos simples até o tecnocrático, segundo Burris (1989), e até o difuso, de acordo com Hatch (1997) e Carvalho (1998).

Burris (1989) expõe a evolução do controle, desde o controle pré-capitalista - que foi centrado em torno da produção familiar e das organizações de ofício, baseadas no aprendizado (controle patriarcal e teocrático) - até o controle tecnocrático, difundido a partir dos anos de 1960 e cuja base é a experiência ou perícia técnica, com equipes organizacionais trabalhando e em que há um controle menos coercivo e aparente que o controle simples. Nesse processo de evolução do controle chega-se ao controle difuso (CARVALHO, 1998), que se baseia em valores culturais. Nesse processo evolutivo, de acordo com as transformações capitalistas, o desenvolvimento desigual e a coexistência de estruturas diferentes de controle passaram a ser encontradas em uma mesma organizaçãoe junto a isso se desenvolveram formas alternativas de controle (BURRIS, 1989). Tal processo, segundo Carvalho (1998, p.2), também

se manifesta na emergência de uma nova dinâmica do sistema fabril caracterizada pela separação do trabalhador dos meios de produção e a concentração da mão-de-obra nas fábricas urbanas. A aparição da alienação por um lado e a divisão do trabalho, por outro, são conseqüências visiveis que revolucionaram o processo de trabalho.

Vê-se, então, a passagem de um controle pré-capitalista para o controle simples.

Quando surgem as empresas maiores, com uma nova organização do trabalho, o controle simples entra em decadência e surgem alternativas para o mesmo, através do controle técnico, burocrático e do profissional (BURRIS, 1989). As supervisões evoluem nessas organizações, sendo desenvolvido com isso o controle técnico, ou seja, um controle basicamente voltado para o funcionamento das máquinas que, segundo Motta (2002), vai estar baseado em parâmetros altamente especializados, com as tarefas operacionais rotinizadas e simples, e com os procedimentos no núcleo operacional muito padronizados. É a máquina ditando o ritmo de trabalho rotineiro dos funcionários. Por sua vez, o primeiro exemplo de controle hegemônico, ou seja, controle em que não há mais - como nos controles simples e técnico, ditos como dominantes - uma supervisão rígida e direta, é o controle burocrático, já que, segundo Mintzberg (1995), é baseado em normas escritas e na hierarquia.

Burris (1989) e Carvalho (1998) caracterizam o controle burocrático através de atividades administrativas mais qualificadas e agrupadas por função. A afirmação de Carvalho (1998, p.2) é que a burocracia se configura

como o primeiro modelo de organização que utiliza mecanismos indiretos e menos visíveis de controle, ao inscrever a regulamentação das atividades, a especialização, a hierarquia e a divisão do trabalho em um conjunto de mecanismos impessoais.

A ênfase não é a pessoa e sim o cargo.

Para a tipologia de controle organizacional, enquadram-se três tipos de controle: direto, estrutural e difuso. O controle direto é exercido em organizações totais como fábricas, indústrias e asilos, afirma Hatch (1997). Aqui, a subordinação real do trabalho é ponto importante. Torna-se mais importante a supervisão direta. Para Mintzberg (1995), essa supervisão seria a coordenação realizada por uma pessoa que assume o trabalho dos outros, dando instruções e monitorando suas ações. Nas organizações totais, segundo Hatch (1997), o alvo do controle seria a utilização do corpo e a base para o engajamento das pessoas nessas organizações é coercitiva, ou seja, o controle é completamente intrusivo.

O segundo tipo de controle identificado é o estrutural, que se manifesta em organizações mais burocratizadas (mediante normas escritas) e por uma estrutura hierárquica, no qual as tarefas passam a ser mais especializadas. São normas estabelecidas previamente. As tarefas que necessitam de uma maior qualificação, como as atividades administrativas, exigem esse controle. Em tal caso, os requisitos técnicos e a complexidade irão 
indicar previamente a função, de forma específica e especializada, de cada profissional. Cada profissional, segundo Ouchi (1980) e Mintzberg (1995), fica enquadrado em um ajuste burocrático, por isso a utilização de mecanismos impessoais de controle (CARVALHO, 1998). Hatch (1997) e Silva (2003) salientam que a base do engajamento para esse tipo de controle é o cálculo. Por essa impessoalidade e ausência de supervisão direta é que o controle estrutural pode também ser conhecido por burocrático ou, conforme afirma Perrow (1990), menos intrusivo.

No que tange ao controle difuso, é importante salientar que Faria (2004, p.79) o expõe como um tipo desenvolvido por vínculo e no qual se trabalha com o

seqüestro da subjetividade [...], e que assim as empresas, para despertar os valores corporativos, a integração e os laços de lealdade, apelam para treinamentos de sobrevivência [...], e fazem com que estes fiquem mais seduzidos e mais vinculados à organização.

É um controle baseado na ideologia e identificação como base de engajamento (SILVA, 2003). Está basicamente relacionado aos símbolos e valores culturais, como afirma Ouchi (1980) ao tratar dos clãs, e segundo Courpasson (2000), ao tratar do controle por pares. As pessoas aqui comungam de uma visão de mundo semelhante. Por isso Perrow (1990) o chama de controle não-intrusivo. A persuasão e o consenso fazem parte desse tipo de controle (CARVALHO, 1998; COURPASSON, 2000; HATCH, 1997 e SILVA, 2003).

\section{Metodologia}

Este artigo é parte de uma análise sobre o processo de "empresarização" e sua influência quanto aos mecanismos de controle organizacional de sete clubes de futebol profissional de Santa Catarina que participaram da primeira divisão do Campeonato Estadual entre 2000 e 2004. Neste estudo, a escolha para a análise recaiu no Figueirense Futebol Clube (Figueirense), pois este reúne características que permitem situá-lo como caso ilustrativo das questões que permeiam esta análise e por sua representatividade no atual cenário futebolístico brasileiro.

Este artigo caracteriza-se como um estudo de caso de natureza descritivo-interpretativa (MARCONI; LAKATOS, 1990; TRIVIÑOS, 1987), pois ao mesmo tempo em que o objetivo foi descrever a transformação do controle no clube de futebol catarinense, a partir da análise do processo de "empresarização", buscou-se interpretar suas implicações organizacionais. Nesse sentido, o artigo procura captar não apenas a aparência do fenômeno, mas também sua essência (TRIVIÑOS, 1987). Desse modo, a pesquisa permitiu trazer à tona, as possíveis características de transformação do controle existentes nas organizações investigadas, a partir da percepção de seus dirigentes, gerentes e funcionários antigos que fizeram parte de momentos distintos da história do clube. A escolha do Figueirense ocorreu de modo intencional e não-probabilístico (MARCONI e LAKATOS, 1990). Assim, foram realizadas observações no cenário do futebol, bem como efetuadas entrevistas semi-estruturadas com esses informantes-chave que atuam na arena do futebol brasileiro. Foram ainda coletados numerosos documentos impressos e eletrônicos que permitiram o estudo do objeto em questão.

Nesta pesquisa a interpretação dos discursos obtidos nos dados primários e secundários foi efetuada com o intuito de verificar os pressupostos estabelecidos no estudo e corroborar a explicação teórica apresentada (MARCONI; LAKATOS, 1990; TRIVIÑOS, 1987). A interpretação do conteúdo das entrevistas e dos documentos conseguidos tiveram como eixo de interpretação a abordagem teórica construída neste estudo. As análises aqui apresentadas compreendem a interpretação dos autores sobre os dados que têm sido coletados ao longo dos últimos quatro anos. Portanto, espera-se, através dessas interpretações, verificar pontes entre os diversos discursos relevantes, visando compreender, de forma mais completa, as dimensões envolvidas no estudo do fenômeno pesquisado. 


\section{Do futebol lúdico ao futebol-empresa}

Até 1930, aproximadamente, o futebol se assentava na lógica de práticas dissociadas da eficiência, da observância de normas e de objetivos organizacionais a atingir. Os primeiros clubes e associações emergiram de grupos sociais nos quais a confiança mútua, o personalismo e o delineamento não-normatizado nem formalmente estabelecido caracterizavam os relacionamentos, as ações e o cotidiano. A divisão das iniciativas não se caracterizava pela divisão de trabalho tecnocrático, centrado na profissionalização e na especialização, nem na repartição horizontal e vertical das responsabilidades. Respondia a uma divisão determinada pela participação voluntária e pelo espírito coletivista (HEINEMANN, 1999).

As décadas de 1930 e de 1940 foram de consolidação do profissionalismo no futebol brasileiro (BRUNORO, 1997). Já em 1931, depois da Copa do Mundo de 1930, no Uruguai, os melhores jogadores brasileiros, como Domingos da Guia e Leônidas da Silva, foram à Europa para jogarem como profissionais remunerados. Desde então, clubes europeus como o Barcelona, da Espanha (contratando Fausto, então jogador do Vasco) e Lazio, da Itália (contratando 10 jogadores brasileiros de uma só vez), dentre outros, começaram a se interessar por jogadores brasileiros. Entretanto, a busca por uma consciência profissional no futebol brasileiro só veio em 1976, quando a Lei $n^{\circ} 6.354$ fez com que todos os jogadores do país trabalhassem com carteira assinada, com os benefícios da Consolidação das Leis do Trabalho (CLT), com férias e Fundo de Garantia por Tempo de Serviço (FGTS). Além disso, essa lei deu direito ao passe livre ao jogador com mais de 32 anos de idade. Em 1980 é então criada a Confederação Brasileira de Futebol (CBF).

A primeira lei a causar as maiores alterações na legislação do futebol só ocorreu em 1993, quando Arthur Antunes Coimbra, o Zico, então secretário de Esportes do governo federal, elaborou a lei (Lei Zico) de $\mathrm{n}^{\circ}$ 8.672, prevendo a possibilidade de criação de clubes-empresa no Brasil. Édson Arantes do Nascimento, o Pelé, quando ministro dos Esportes, em 1996, alterou a assim denominada "Lei do Passe", propiciando aos jogadores o direito de serem seus próprios "donos". Surgiu então a Lei no 9.615/98, ou seja, a "Lei Pelé". Porém, essa alteração foi contestada e Pelé voltou atrás, criando assim uma tabela decrescente para o direito ao passe livre: 1997, jogadores com 30 anos; 1998, jogadores com 27 anos; 1999, jogadores com 26 anos; e no ano 2000, todos os jogadores com 25 anos completos. Em 1997, a Casa Civil entregou ao Congresso o Projeto Pelé, que tem como pontos principais a transformação dos departamentos de futebol dos clubes em empresas, embora até hoje a obrigatoriedade da transformação dos clubes em empresas seja opcional.

Bilhões de dólares circulando anualmente fazem do futebol um grande negócio. Como modelo de profissionalismo, temos os clubes do futebol europeu, que estão num nível de evolução muito superior ao dos clubes brasileiros. Contudo, esse nível foi alcançado a partir do momento em que romperam laços paternalistas e amadores, adotando posturas mais profissionais em sua organização, amparadas por estratégias de empresas privadas, com ênfase no marketing, nas finanças, na contabilidade e valendo-se de muitos mecanismos utilizados por empresas que buscam sempre a rentabilidade (JAPIASSU, 1990; PRONI, 2000).

O televisionamento a cabo (pacotes pagos, ou pay per view) é um grande mecanismo empresarial ligado à imagem de um clube de futebol. Ele é parte de um ambiente maior, chamado de consumidores de bens ou serviços ligados ao futebol, e que não participam da produção do espetáculo em si. Esses podem ser os consumidores finais (torcedores) e intermediários (produtores e vendedores de bens necessários à pratica, como a Nike, a Adidas etc.), os patrocinadores, os produtores e os vendedores de espetáculos esportivos e bens associados, dentre outros (AIDAR, 2002). O patrocínio no futebol com a marca da empresa na camisa só começou a ser divulgado no futebol a partir da década de 1980, pois antes havia resistência por parte dos dirigentes e torcedores, salienta Brunoro (1997). 


\section{"Empresarização" e controle organizacional no Figueirense Futebol Clube}

A empresarização do futebol pode ser vista como um termo para indicar o nível em que o clube está na sua transformação e funcionamento como empresa. Todo um discurso para transformar o futebol em esporte profissional e com caráter empresarial vem sendo tratado nos programas esportivos, em livros especializados na área e em jornais, mas há outros fatores a serem tratados nesse campo. Com isso, essa "consciência" empresarial, na tentativa de igualar o futebol brasileiro (considerado amador) ao futebol-espetáculo europeu, está possivelmente interrompida, pois os maiores influenciadores do futebol brasileiro não aceitam tal mudança (dirigentes cartolas, grupos políticos e torcidas organizadas), apesar de que empresas já fazem contratos com alguns clubes no Brasil com esse fim.

Adiante, é apresentado um quadro explicativo indicando os traços de mercantilização do futebol brasileiro, elaborado em função dos parâmetros (traços) estabelecidos por Solé (2004) para o processo de "empresarização".

Quadro. 1 - Traços de empresarização do futebol

\begin{tabular}{|c|c|}
\hline $\begin{array}{l}\text { Traço indicador de } \\
\text { empresarização }\end{array}$ & Indicadores \\
\hline \multirow{4}{*}{$\begin{array}{l}\text { Concepção, produção e venda de } \\
\text { mercadoria }\end{array}$} & Produção de mercadoria \\
\hline & Produtos vendidos \\
\hline & Tipos de produtos \\
\hline & Serviços vendidos \\
\hline \multirow{4}{*}{$\begin{array}{l}\text { Organização com escritura e } \\
\text { contabilidade }\end{array}$} & Uso de documentos com informações financeiras \\
\hline & Contratos escritos \\
\hline & Registros \\
\hline & Prestação de contas \\
\hline \multirow{3}{*}{ Propriedade privada } & $\begin{array}{l}\text { O pertencer da organização para responsabilidade de uma pessoa } \\
\text { jurídica ou grupo majoritário }\end{array}$ \\
\hline & Relação entre quem possui e os que não possuem tal propriedade \\
\hline & Forma jurídica \\
\hline Organização salarial & Assalariados ou não-assalariados \\
\hline \multirow{4}{*}{ Lucro } & Investimentos \\
\hline & Retorno em dinheiro \\
\hline & Perspectivas de retorno \\
\hline & Obtenção de recursos \\
\hline Linguagem & Tipo de linguagem percebido \\
\hline
\end{tabular}

No dia 12 de junho de 1921 foi fundado o Figueirense Futebol Clube e sua origem remonta ao papel de jovens amigos ligados ao remo. Há dois momentos na história do clube: o primeiro vai de sua fundação ao ano de 1998 e o outro de 1999 aos dias atuais.

O primeiro momento da história foi num contexto em que as ações do clube baseavam-se numa abordagem amadorística da gestão organizacional, com dirigentes personalistas e torcedores apaixonados que desenvolviam suas ações desprovidas de quaisquer parâmetros profissionais e de eficiência. À medida que o departamento de futebol foi crescendo e as exigências quanto a resultados dentro e fora do campo aumentavam, o clube se endividou de tal forma que foi decidido em conselho arregimentar empresários interessados em investir na recuperação do clube. O projeto era criar uma empresa. O clube passou, então, num segundo 
momento de sua história, a caminhar rumo à profissionalização de seus modelos de gestão calcados em critérios de competência, produtividade e eficiência.

Em 1999 foram desenvolvidos esforços para profissionalizar a gestão do clube, contratando-se um diretor executivo que a partir daquela data responderia pela gestão do clube. Os interesses subjacentes a esse processo de mudança, com base no discurso dos entrevistados, foram adequar o clube às necessidades de modernização presentes na arena do desporto brasileiro e proporcionar ao clube uma estrutura administrativa e financeira equilibrada. No que tange às questões de "empresarização", pode-se perceber:

\section{a) Concepção, produção e venda de mercadoria}

Até 1999, a principal fonte de renda do clube advinha de bilheterias e de doações dos dirigentes. No contexto atual, suas fontes de recursos se ampliaram, de modo que além das bilheterias, tem-se cotas de TV e negociações de jogadores (leia-se "produto/mercadoria"), publicidade e patrocínio (exemplo: placas publicitárias no estádio) e licenciamento da marca "Figueirense".

\section{b) Organização com escritura e contabilidade}

Até meados da década de 1970, não havia no Figueirense documentos com informações financeiras, contratos escritos nem prestação de contas. Só existia o livro-caixa para registrar a entrada e a saída de recursos. Da mesma forma, não havia relação com nenhuma organização que requisitasse contrato escrito. A gestão era amadora; não tinha nada de empresarial.

A partir de 1999, houve uma reorganização estrutural que envolveu a criação de um departamento contábiljurídico, semelhante ao de uma empresa. Houve um momento na história do clube em que foi formalizada uma parceria de gestão do departamento de futebol com a empresa CSR, dos jogadores Rivaldo e César Sampaio (que já defenderam a Seleção Brasileira). A empresa não se interessou em manter a parceria, e o clube tem procurado novo parceiro para a gestão do futebol.

Quando à relação de patrocínio, vale destacar que é mera ação de marketing o discurso dos dirigentes do clube de que o patrocinador não influencia a gestão, figurando apenas como fonte de recursos, pois ele fornece material em troca de propaganda. Recentemente, para reformar seu estádio, o Figueirense firmou contrato com uma empresa americana.

\section{c) Propriedade privada}

De sua origem até o início da década de 1990, o Figueirense funcionou como uma sociedade sem fins lucrativos. Posteriormente, para se adequar ao novo marco legal do futebol (Lei Pelé e atualizações), a nova diretoria que assumiu o clube no fim daquela década implantou a Figueirense Participações, uma sociedade anônima de capital fechado de propriedade dos empresários do conselho de gestão do clube.

O clube continua como "um clube social", mas em 1999 a Figueirense Participações iniciou o processo de mudança. Em 2001 foi assinado um contrato de gestão do Figueirense. Hoje a gestão do clube é de responsabilidade da Figueirense Participações. É um contrato de 20 anos mais 10, pelo qual o Figueirense transfere a gestão do futebol, da marca, da imagem e demais aspectos da gestão do departamento de futebol para a Figueirense Participações. Assim, o clube continua sendo uma associação sem fins lucrativos, mas dentro de sua sede há uma empresa privada, constituída para comandar o clube em todas as suas ações hoje em dia e nos próximos 30 anos.

\section{d) Organização salarial}

A presença de assalariados no clube não é recente. Na década de 1970, de acordo com pesquisa feita no próprio clube, o Figueirense já tinha funcionários assalariados, mas em pequeno número, apenas o zelador e a lavadeira. Não havia remuneração para o roupeiro e o médico, que trabalhavam por "amor de torcedor". 
Atualmente, o clube conta com 160 funcionários - 110 deles são jogadores do clube, de juniores a profissionais - e todos são remunerados; exceto os diretores, que prestam serviço voluntariamente. Em dias de jogos oficiais, o clube contrata funcionários terceirizados para exercerem atividades de segurança no estádio. Em pesquisa, foi constatado que essa última ação é exclusividade deste clube, em comparação com os demais clubes da divisão principal do campeonato estadual catarinense. Embora tal questão pareça extrapolar o indicador em análise, não pode ser desconsiderada para efeito de compreensão do processo de "empresarização" do Figueirense.

\section{e) Lucro}

Para obterem lucro, normalmente, as empresas fazem investimentos. O Figueirense, como uma instituição sem fins lucrativos, mas administrada por uma empresa, formada para comandar o clube, apresenta investimentos significativos. Primeiro, quando se nota esforços para as reformas do estádio e do centro de treinamento. Outros investimentos com o passar do tempo envolveram ações para formação e compra de passes de atletas. Todas essas ações de investimento serão mantidas, segundo o atual discurso da Figueirense Participações.

\section{f) Linguagem}

Outro indicador evidenciado é o da linguagem empresarial. Pelos comentários dos entrevistados e pelas pesquisas nos materiais do clube, foi identificada no Figueirense uma tendência ao comportamento empresarial. $\mathrm{O}$ atual presidente do conselho deliberativo considera o torcedor patrimônio fundamental e cliente. $\mathrm{O}$ futebol é considerado negócio, de modo que, do ponto de vista da gestão empresarial, são desenvolvidos esforços para dar ao Figueirense uma estrutura administrativa e financeira que possibilite ao clube manter o bom equilíbrio orçamentário. Além disso, foi implantado um setor de gestão de pessoas que cuida da definição do perfil exigido hoje de funcionários, visando aperfeiçoar o processo de seleção e recrutamento, uma vez que há preocupação com o treinamento das pessoas, com a capacitação etc.

Paralelo aos traços empresariais demonstrados, há um aspecto diretamente relacionado com os mesmos, e a partir daí se pode começar a entender o quanto os meios de organização interna são transformados. Esse aspecto é o controle organizacional, já que tende a ser modificado justamente devido à transformação da antiga forma de organização dos clubes de futebol na forma atual, tida como "ideal". É a compreensão de valores que possivelmente se alteraram devido a pressões do ambiente, através de mecanismos empresariais, que buscam se tornar institucionalizadas. Nessa perspectiva não se pode deixar de enfatizar os três tipos básicos de controle existentes e como eles são transformados. São eles:

- controle direto (baseado em ordens expressas e coercitivas);

- controle estrutural (baseado em regras formais, normas escritas, cargos bem definidos, regras impessoais etc); e

- controle difuso (baseado em valores culturais próprios de cada lugar ou clube, a partir de premissas estabelecidas por um determinado grupo que convive na organização do trabalho).

A idéia é que com o aumento das necessidades de uma organização, como mais funcionários e mais exigências financeiras, os clubes passem de uma organização baseada no controle difuso (ou seja, cultural) para uma de controle mais estrutural, em que fazer parte da organização tem o mesmo sentido de estar trabalhando numa empresa.

O quadro 2 sintetiza os aspectos de controle organizacional através de indicadores. 
Quadro 2 - Tipos de controle organizacional

\begin{tabular}{ll}
\hline Controle & Características \\
\hline \multirow{2}{*}{ Direto } & Clareza (tipo) de ordens \\
\cline { 2 - 2 } & Rigidez (regime) de horário \\
\cline { 2 - 2 } Supervisão direta \\
\hline Estrutural & Autoridade (tipo) coercitiva \\
\hline Formalização \\
\cline { 2 - 2 } Difuso & Profissionalização \\
\hline
\end{tabular}

Fonte: Elaborado pelos autores

Tendo em vista o objetivo central deste artigo que é analisar a influência exercida pelo processo de "empresarização" sobre o controle organizacional do Figueirense Futebol Clube, e com base nos quadros analíticos dispostos anteriormente (quadros 1 e 2), pode-se afirmar que, quanto ao controle direto neste clube, na época de sua fundação, segundo as informações obtidas nas entrevistas, o indicador "clareza das ordens" teve um nível baixo de verificação, pois não havia rigidez no cumprimento de horários e as informações não fluíam com nitidez. Quanto ao quesito "supervisão", praticamente não havia supervisão direta, de forma coerciva. A decisão era centralizada no presidente, como ainda acontece hoje. Porém, atualmente são observadas evidências de supervisão direta, de rigidez no horário e de autoridade coercitiva.

Quanto às transformações no controle estrutural e, especificamente à formalização, foi mencionado que as reuniões eram realizadas com atas, mas que não havia formalidades em relação aos processos de comunicação e de trabalho. Como era uma organização comandada por amigos, no primeiro momento da história do clube, tudo era realizado verbalmente. Quase não haviam requisitos técnicos dentro do Figueirense, salientam os discursos de seus dirigentes, assim como não era prática acontecer isso. Antes, os níveis hierárquicos existiam simbolicamente. Tudo era realizado na hora e por todos, que tinham que se juntar para desenvolver alguma função. Hoje em dia o que ocorre é que o Figueirense tem uma diretoria mais bem definida, composta por um presidente do conselho deliberativo, do conselho administrativo, pelas demais vice-presidências (administrativa, financeira e de comunicação) e por cada diretoria com suas atividades. A tomada de decisão tende a ser descentralizada em alguns níveis abaixo da cúpula.

No Figueirense, da época de sua fundação até 1998, tudo era decidido pelo presidente juntamente com os convidados para os cargos diretores que o auxiliavam. Hoje, há um processo de gestão compartilhada entre o Figueirense Futebol Clube e a Figueirense Participações. As decisões gerenciais do dia-a-dia são com o dirigentes do Figueirense, mas as decisões estratégicas e as decisões mercadológicas - como obtenção de patrocínios, negociação de atletas e negociação do direito de participação - são de responsabilidade da Figueirense Participações.

Com relação à profissionalização do clube, percebeu-se um deslocamento das ações puramente movidas pelo "amor à arte" - não se pensava nem se concebia a necessidade de ter profissionais credenciados na direção das ações futebolísticas do clube - para o atual contexto de profissionalização mediante contratação de quadro de funcionários-dirigentes credenciados. O compartilhamento de valores e a ênfase no controle difuso podem ser percebidos na história do Figueirense, quando os dados das entrevistas apontam que antes se tinha "a 
administração do futebol como um lazer e o futebol era apenas paixão". Antes os programas de ação no clube eram feitos sem planejamento; agora, as ações partem de um planejamento estratégico.

\section{Considerações finais}

Neste artigo foi analisado o processo de "empresarização" e sua relação com o controle organizacional no Figueirense Futebol Clube; clube de futebol que disputou a primeira divisão (série "A1") do campeonato catarinense de 2000 a 2004.

A perspectiva do estudo foi longitudinal e esse processo foi estudado desde a fundação (histórico) do clube até o dias atuais. No estudo, percebeu-se que o clube vem passando por muitas mudanças, tanto nas suas configurações internas quanto nas normas que regulam suas atividades, fruto de uma adequação à nova lógica que impera no contexto desportivo brasileiro, que é a de mercado. Ficou identificado que o processo de "empresarização", mesmo ocorrendo atualmente, ainda de forma pouco considerável, teve uma tendência evolutiva mais clara nos traços: "organização com escritura e contabilidade", "organização salarial" e na "linguagem".

Seguindo esses três traços - considerados os mais destacados, no sentido de um processo de "empresarização" nos clubes -, os dois primeiros têm relação direta com o tipo de controle estrutural, através de normas escritas, profissionalização, complexidade e requisitos técnicos. Da mesma forma, quanto aos traços "organização salarial" e "linguagem" (utilizada pelos integrantes do clube) foi possível identificar uma amenização em relação ao controle difuso, no sentido de valores promulgados, na seleção e nos programas de ação.

Foi constatado que no Figueirense o controle difuso foi historicamente predominante, demonstrando um caráter normativo da organização futebolística catarinense, segundo Etzioni (1967) e Hatch (1997). Atualmente, esse tipo de controle é mais ameno, mais ainda predominante. O controle difuso - considerado menos intrusivo por Perrow (1990) e completamente pró-ativo por Carvalho (1998) - sofreu esse declínio a partir do momento em que mecanismos impessoais e formais passaram a fazer parte da organização do trabalho no clube. A amenização do controle difuso não retirou sua importância, nem se pode deixar de considerar que está em desenvolvimento um novo conteúdo do controle difuso no clube, associado a novos valores, notadamente os de eficiência, profissionalismo e de mercado.

Em uma organização burocrática, os mecanismos de controle são, sobretudo estruturais, segundo Motta (2002). O controle se fundamenta na normatização por escrito, numa estrutura hierárquica mais definida e numa maior especialização de funções. Tal tipo de controle teve uma evidente evolução no sentido ascendente, pela implantação de regras, o recurso às comunicações internas, a utilização de atas de reuniões e pela incorporação de um maior número de profissionais especializados ao quadro de pessoal do clube.

Uma crescente complexidade nas funções, tal como descrita por Hall (1984), pôde ser identificada tanto na diferenciação vertical (número de níveis existentes entre o topo da hierarquia e a base) como na horizontal (subdivisão das tarefas desempenhadas pelos membros da organização). Mecanismos impessoais de controle passaram a fazer parte dessa organização futebolística estudada em Santa Catarina, considerando-se o interesse contínuo de buscar uma maior formalização de ações, ou seja, planejando regulamentos e padrões que possam ser utilizados para controlar o comportamento organizacional.

A análise permite supor que o processo de empresarização, tal como descrito por Solé (2004) - mesmo não sendo intenso e homogêneo no clube estudado - parece ter impacto sobre os tipos de controle mais enfatizados nessa organização, sobretudo, na observação de um maior destaque para o controle estrutural, como já descrito. Isso é percebido claramente quando o Figueirense constituiu uma empresa para gerenciar seus negócios.

Com a utilização de mecanismos contábeis, jurídicos, financeiros e a formalização nas ações do clube, configura-se uma estrutura mais complexa, com horários de trabalho definidos (mediante utilização de livro ou 
cartão ponto), assim como uma tendência de recorrer a currículos para seleção de pessoal, além da atualização dos ativos e passivos do clube feitos de forma mais completa, caracterizando ações burocráticas que começam a se desenvolver na maioria dos clubes estudados, numa migração para o controle estrutural.

No que tange ao traço de "empresarização" do uso de linguagem mercadológica, foi identificada a adoção de novos parâmetros com base em critérios de organizações que visam ao lucro. O próprio diretor do Figueirense salientou que o cargo a ser ocupado no clube está mais voltado ao fato de que o clube não deve ser administrado por paixão. Além disso, ele falou de regras e metas financeiras a serem atingidas, as quais vem monitorando. A partir dos traços estudados, o processo de empresarização parece efetivamente relacionado com as transformações do controle. Ainda que esse processo não apresente intensidade em todas as suas características, as consequiências no desenvolvimento do controle estrutural já podem ser percebidas.

Se funcionários já começam a reclamar dos salários atrasados indo à Justiça cobrar seus direitos, se o torcedor passa a ser visto como um cliente, se outras organizações (no caso empresas privadas) passam a ser administradoras de alguns clubes, se cada vez mais pessoas assalariadas e formadas em determinadas áreas começam a compor o quadro integrante dos clubes, acredita-se que o caráter difuso tende a migrar em alguns pontos para o estrutural. É o início da burocratização dessas organizações. Essas questões podem ser explicadas através do ideal do capitalismo, da estrutura empresarial, de modelos burocráticos e de um ideal de modernidade. Se os clubes tendem a passar para um modelo mais burocratizado, pode-se também concluir que houve um movimento de transformação no seu controle organizacional. Além do mais, tal transformação pode ter sido alavancada principalmente por um processo de mercantilização e de "empresarização" das organizações. Este significa a crescente utilização de mecanismos empresariais pelas organizações como meio de uma nova forma organizacional, inclusive, pelos clubes de futebol.

Acrescenta-se a isso o fato de que o conteúdo dos valores compartilhados parece estar mudando de um conteúdo que valorizava a paixão pelo clube (o fato associativo que é o futebol) para um conteúdo que privilegia valores como desempenho, competição, eficiência e parâmetros mercantis. Então, que significado têm essas transformações no contexto brasileiro? De que maneira o estudo contribui para a apropriação de teorias? Fica patente neste estudo que o futebol cada vez menos serve para proporcionar o alívio das tensões do trabalho. Ao contrário, ele incorporou essas tensões, as mesmas exigências angustiantes de resultados, eficiência, concorrência, tempo etc.

Quando o mercado dita as regras e o lucro se afirma como fim último, tudo se torna negociável: jogadores, torcedores e clubes do coração. Enfim, os símbolos perdem seu valor e se tornam parte de um jogo de imagem sem qualquer relação com o que outrora representaram. A perda da dimensão substantiva de atividades como o futebol é a preocupação de fundo que perpassa este artigo, que questionou sobre o que irá substituir não apenas as práticas desportivas, mas também a cultura e o ócio na cimentação social dos indivíduos; os seus laços de pertença, a sua identidade cultural. Essas atividades estão abandonando seus objetivos originais: perde-se o lúdico e o livre, o que não é construído sobre cálculos de retorno, o que não tinha obrigatoriamente um fim e um resultado final. Hoje, são oportunidade de negócios. Dessa forma, este artigo se enquadra no escopo daqueles que procuram entender o processo de mudanças na sociedade como a perda de espaço das práticas de ócio, num contexto de amplo domínio do modelo capitalista de desenvolvimento, que traz consigo uma crescente subordinação à racionalidade instrumental que facilita o ajuste às leis de mercado. 


\section{Referências}

AIDAR, A. C. K. A nova gestão do futebol. 2.ed. Rio de Janeiro: FGV, 2002.

ALVES, S. Os tipos ideais e a ação social. In: Racionalidade, carisma e tradição nas organizações empresariais contemporâneas. Recife: Editora da UFPE, 2003. p.23-28.

BRUNORO, J. C. Futebol 100\% profissional. São Paulo: Gente, 1997.

BURRIS, B. H. Technocratic organization and control. Organization Studies, v. 10, n. 1, p. 1-22, 1989.

CARVALHO, C. A. Poder, conflito e controle nas organizações modernas. Maceió: Ufal, 1998.

. Configuração do campo da cultura no contexto da incorporação da lógica mercantil e os novos atores organizacionais. 2003. Projeto CNPq.

; GONÇALVES, J. C.; ALCÂNTARA, B. C. O lúdico, o profissional e o negócio no futebol. In: CARVALHO, C. A.; VIEIRA, M. M. F. (Org.). Organizações, cultura e desenvolvimento local: a agenda de pesquisa do Observatório da Realidade Organizacional. Recife: Edufepe, 2003. cap.12, p.235-254.

CHIAPPELLO, È. Les typologies des modes de contrôle et leurs facteurs de contingence: un essai d'organisation de la littérature. Comptabilité-contrôle-audit, tome 2, v.2, sept. 1996.

COURPASSON, D. Managerial strategies of domination - power in soft bureaucracies. Organization Studies, v.21, n.1, p.141-161, 2000.

DELLAGNELO, E. L.; MACHADO-DA-SILVA, C. L. Literatura sobre novas formas organizacionais: onde se encontram as evidências empíricas de ruptura com o modelo burocrático de organizações? In: ENCONTRO ANUAL DA ASSOCIAÇÃO NACIONAL DOS PROGRAMAS DE PÓSGRADUAÇÃO EM ADMINISTRAÇÃO, 24., 2000, Florianópolis. Anais... Rio de Janeiro: Anpad, 2000. 1 CD-ROM.

ETZIONI, A. Organizações modernas - São Paulo: Pioneira, 1967.

FARIA, J. H. Economia política do poder. Curitiba: Juruá, 2004.

GONÇALVES, J. C. S.; MAGALHÃES FILHO, P. A. 0; ALCÂNTARA, B. C. S. Do ócio ao negócio: a expansão da lógica de mercado no futebol de Pernambuco. In: COLÓOUIO INTERNACIONAL SOBRE PODER LOCAL, 9., 2003, Salvador. Anais... Salvador: Nepol/UFBA, 2003. 1 CD-ROM.

HALL, R. H. Organizações: estruturas e processos. Rio de Janeiro: Prentice Hall do Brasil, 1984.

HATCH, M. J. Organization theory. Modern, symbolic and postmodern perspectives. Oxford: Oxford University Press, 1997. cap.9, p.297310.

HEINEMANN, K. Sociologia de las organizaciones voluntaries: el ejemplo del club deportivo. Valencia: Tirant lo Blanch, 1999.

HOFSTEDE, G. Management control of public and not-for-profit activities. Accounting, Organizations and Society,v.6, n.3, p.193-211, 1981 .

JAPIASSU, M. Primeiro tempo - pontapé inicial. In.: WITTER, J. S. 0 que é futebol. São Paulo: Brasiliense, 1990. p.19-21.

KALBERG, S. Max Weber's types of rationality: cornerstones for the analysis of rationalization processes in history. American Journal of Sociology, v.85, n.5, p.1145-1179, 1980.

MAGALHÃES FILHO, P. A. O. A configuração organizacional dos clubes de futebol do estado de Pernambuco e a expansão da lógica de mercado. 2003. 140f. Dissertação (Mestrado em Administração) - Universidade Federal de Pernambuco, Recife, 2003.

MARCONI, M. A.; LAKATOS, E. M. Técnicas de pesquisa: planejamento e execução de pesquisas, amostragens e técnicas de pesquisa, elaboração, análise e interpretação de dados. 2.ed. São Paulo: Atlas, 1990.

MINTZBERG, H. Criando organizações eficazes: estruturas em cinco configurações. São Paulo: Atlas, 1995.

MOTTA, F. C. P. Teoria geral da administração. São Paulo: Pioneira, 2002.

OUCHI, W. Markets, bureaucracies and clans. Administrative Science Quarterly, v.25, Mar. 1980.

PERROW, C. B. Análise organizacional: um enfoque sociológico. São Paulo, Atlas, 1990.

PRONI, M. W. A metamorfose do futebol. São Paulo: Unicamp, 2000.

RAMOS, A. G. A nova ciência das organizações.Rio de Janeiro: FGV, 1989. 
SCHUMPETER, J. A. A teoria do desenvolvimento econômico: uma investigação sobre lucros, capital, crédito, juro e o ciclo econômico. São Paulo: Nova Cultural, 1988. p.43-66.

SILVA, R. C. Controle organizacional, cultura e liderança: evolução, transformações e perspectivas. Revista de Administração Pública RAP, Rio de Janeiro v.4, n.37, p.797-816, jul./ago. 2003.

SOLÉ, A. L'entreprise: une invention latine? In: II Colóquio Internacional - Análise de organizações: perspectivas latinas. Salvador: Nepol/UFBA, 2003. p.1-20.

¿Qué es una empresa? Construcción de un idealtipo transdisciplinario. Paris, 2004. (Work paper).

TANNENBAUM, A. S. 0 controle nas organizações. Petrópolis: Vozes, 1975.

TRIVIÑOS, A. N. S. Introdução à pesquisa em ciências sociais: a pesquisa qualitativa em educação. São Paulo: Atlas, 1987.

WEBER, M. Conceitos básicos de sociologia. São Paulo: Moraes, 1987.

Economia e sociedade. Brasilia, DF: Editora Universidade de Brasília, 1991.

Os economistas. São Paulo: Nova Cultural, 1997. Textos selecionados.

A ética protestante e o espírito do capitalismo. São Paulo: Martin-Claret, 2001. 